\title{
OS CONTOS DE FADAS EM PRÁTICAS DE LETRAMENTO COM CRIANÇAS DE 3 E 4 ANOS DE IDADE
}

\author{
Eliane Santana Dias Debus ${ }^{1}$ \\ Vanessa Galdino²
}

\section{RESUMO}

O presente artigo apresenta a pesquisa que teve por objetivo investigar o trabalho com a linguagem escrita e a apropriação da cultura letrada na Educação Infantil a partir dos Contos de Fadas. Para alcançá-lo, realizou-se um trabalho de intervenção com crianças de 3 e 4 anos de um Centro de Educação Infantil da rede pública do município de Tubarão (SC). Os instrumentos utilizados na coleta de dados foram: registro escrito (diário de campo) e fotográfico. Para a análise dos dados, recorreuse ao referencial teórico dos estudiosos Baptista (2012; 2010), Machado (2002), Mello (2010) e Soares (2003), entre outros, e enfatizou-se a leitura e a escrita como produção cultural desde a Educação Infantil, focalizando a Literatura Infantil. Constatou-se que os contos de fadas possibilitam práticas de letramento que ampliam o repertório literário da criança pequena.

Palavras-chave: Educação Infantil; Letramento; Contos de Fadas.

\section{THE FAIRY TALES IN LITERACY PRACTICES WITH CHILDREN 3 AND 4 YEARS-OLDS}

\begin{abstract}
This paper presents a research which aimed to investigate written language and appropriation of literate culture in Child Education, based on fairy-tales. In order to do so, an intervention was carried out with 3 and 4 year-olds enrolled at a public Child Education Center in Tubarão town (SC). The instruments used for data collection comprised written (field journal) and photographic records. Regarding data analysis, theoretical frameworks put forward by Baptista $(2010,2012)$, Machado (2002), Mello (2010), and Soares (2003), among others, were adopted. that the fidings point to the fairy tales enable literacy practices that expand the literary repertoire of the small child.
\end{abstract}

Keywords: Child Education; Literacy; Fairy tales.

\section{LOS CUENTOS DE FADAS EN PRÁCTICAS DE ALFABETIZACIÓN CON NIÑOS DE 3 Y 4 AÑOS DE EDAD}

\section{RESUMEN}

Este artículo presenta una investigación cuyo objetivo fue investigar el trabajo con un lenguaje escrito y la apropiación de la cultura de las letras en la Educación Infantil desde los Cuentos de Hadas. Para alcanzarlo fue realizado un trabajo de intervención con niños de 3 y 4 años de un Centro de Educación de Niños de la red pública del municipio de Tubarão (SC). Los instrumentos utilizados en la colección de datos fueron: registro escrito (diario de campo) y fotográfico. Para el análisis de los datos fue recurrido al referencial teórico de los estudiosos Baptista (2012; 2010), Machado (2002), Mello (2010) y Soares (2003), entre otros, y enfatizada la lectura y la escrita como producción

\footnotetext{
${ }^{1}$ Doutorado em Lingüística e Letras pela Pontifícia Universidade Católica do Rio Grande do Sul, Brasil (2001) Professor Titular da Universidade Federal de Santa Catarina , Brasil. E-mail: <elianedebus@hotmail.com>

2 Graduanda em Pedagogia (Unisul), Especialista em Educação Infaltil (NDI/UFSC), professora da Rede Municipal de Tubarão. E-mail: <vagaldino@hotmail.com>
} 
cultural desde la Educación Infantil, focalizando la Literatura Infantil. Fue constatado que los cuentos de hadas posibilitan prácticas de enseñanza de las letras que pueden ampliar el repertorio literario de los niños pequeños.

Palabras-clave: Educación Infantil; Alfabetización; Cuentos de hadas.

\section{INTRODUÇÃO}

A educação da primeira infância tem sido, nos últimos anos, tema constante entre pesquisadores e professores brasileiros, como comprova o trabalho de Strenzel (2000) ao debruçar-se sobre as pesquisas em nível de Pós-Graduação realizadas no período de 1983 a 1998, evidenciando um acentuado crescimento, em particular em nível de mestrado. Uma década depois, Silva, Luz e Faria Filho (2010, p. 96), embora constatem o acréscimo de pesquisas nesse nível da Educação Básica, acreditam ainda ser baixa as linhas de pesquisas na Pós-Graduação em Educação em relação ao "número bastante razoável de grupos de pesquisa em educação infantil, infância e criança". Outros trabalhos, como o de Buss-Simão, Rocha e Gonçalves (2015), onde aparece um levantamento da produção científica brasileira a partir do banco de teses e dissertações da CAPES entre os anos de 2008 e 2011, com foco na docência com crianças de 0 a 3 nos de idade, evidencia que, "embora o número de trabalhos sobre as crianças de zero a três anos seja muito inferior ao restante, os números das últimas Reuniões da ANPED são otimistas e expressam a preocupação da área sobre a situação da creche e das crianças pequenas" (BUSS-SIMÃO; ROCHA; GONÇALVES; 2015, p. 104).

Para Baptista (2012), com o reconhecimento de que a Educação Infantil integra a Educação Básica, um dos principais desafios que surge é a construção de práticas educativas que assegurem, às crianças pequenas, o direito a uma educação de qualidade e, nesse caso em particular, no que se refere à linguagem escrita, sem, no entanto, pensar em práticas de sistematização da alfabetização.

Ao pensar em alfabetização é muito comum a ideia da imagem do código alfabético, em que a criança precisa somente dominar códigos de leitura e de escrita. Nessa perspectiva, a Educação Infantil configura-se como preparação para a alfabetização, no sentido de conhecer letras e associá-las às palavras. Entretanto, os documentos de 
referência para a Educação Infantil, entre eles as Diretrizes Curriculares Nacionais para a Educação Infantil (2010), não se filiam a esse encaminhamento. Neste momento da educação não se busca a sistematização da leitura e da escrita como aquisição do código gráfico, mas uma prática que priorize o uso social da leitura e escrita, como destaca Soares (2003).

Diante de práticas pedagógicas que ainda consideram um trabalho de sistematização da alfabetização na Educação Infantil, ficam alguns questionamentos: o que a criança aprende tem significado para ela? Traçar letras e formar palavras garante a aprendizagem da linguagem escrita? Se a criança interagir com a língua escrita em seus usos e práticas sociais, este aprendizado será diferenciado?

Mobilizada por esses questionamentos e a partir das reflexões realizadas nas disciplinas do curso de Especialização e Docência na Educação Infantil (UFSC, 2015), pólo Tubarão (SC), e da experiência como professora de crianças pequenas, surge a necessidade de um estudo sobre a prática pedagógica na Educação Infantil, que vise a responder aos seguintes problemas de pesquisa: Como garantir, desde a primeira infância, a apropriação d a cultura escrita por meio de práticas de letramento? Quais os caminhos possíveis para essa prática?

Nesse percurso de nos interrogar e, se não, lançar respostas, houve um debruçar investigativamente sobre a prática, e buscou-se, como objetivo, investigar o trabalho com a linguagem escrita e a apropriação da cultura letrada na Educação Infantil a partir de Contos de Fadas. Para alcançar tal objetivo propô-se uma pesquisa de intervenção com uma turma nomeada pela instituição de Creche IV (3 a 4 anos), composta por onze crianças, das quais oito são meninos e 3 são meninas, de um Centro de Educação Infantil da rede municipal de educação do município de Tubarão, sul do estado de Santa Catarina. A escolha da referida turma deu-se pelo fato da pós-graduanda ser a professora regente da mesma.

A partir do projeto institucional Quem conta reconta... faz de conta, proposto a todas as turmas da instituição em foco no ano de 2015, a intervenção ocorreu nos meses de agosto e setembro do referido ano, durante o período matutino, totalizando oito encontros. Para a coleta de dados foram utilizados como instrumentos o registro escrito (diário de campo) e o fotográfico. 
A concepção que se pretende afirmar neste estudo, como referência para a ação pedagógica na Educação Infantil, baseia-se na compreensão das características próprias desta etapa da Educação Básica, ao considerar o modo como as crianças relacionam-se, dão significado e se apropriam da cultura escrita, em particular por meio dos contos de fadas.

Ao consideramos a linguagem escrita, de acordo com a compreensão de Baptista (2010, p. 02), como as "produções que se realizam por meio da escrita e aos resultados do uso social que se faz desse objeto do conhecimento", apresenta-se algumas reflexões sobre a linguagem escrita, alfabetização e letramento com o objetivo de aprofundar tal discussão.

\title{
2. LINGUAGEM ESCRITA, ALFABETIZAÇÃO E LETRAMENTO: NEM TÃO PERTO, NEM TÃO LONGE
}

A ênfase dos estudos sobre a alfabetização até a década de 1970 era, de acordo com Baptista (2010), a conduta observável do ato de ler e escrever. Desse modo, a língua escrita era compreendida como um sistema de transcrição da fala:

\begin{abstract}
Aprender a ler e escrever se traduzia em habilidades observáveis e mensuráveis que, por sua vez, exigiam, para sua apreensão, o desenvolvimento de processos periféricos de tipo perceptível e motor. Tomando-se como pressuposto a existência de dois momentos distintos um primeiro de pré-leitura e pré-escrita e um seguinte de leitura e escrita propriamente dito - o ensino pré-escolar se configurava como um momento de preparação para a alfabetização, encarregando-se de treinar habilidades consideradas pré-requisitos básicos para a efetiva apreensão da leitura e escrita que ocorreria em um momento posterior (BAPTISTA, 2010, pp. 06-07).
\end{abstract}

Ainda segundo a referida autora, a partir da década de 1980, os estudos de Ferreiro e Teberosky (1985) trouxeram uma preocupação com processos mentais, não observáveis diretamente. A concepção que sustentava essa nova forma de compreender a alfabetização era a de que "ler e escrever são atividades complexas, que exigem processos mentais, cognitivos e que, sob esses atos, há um sujeito que pensa, elabora hipóteses e busca construir significados para seus atos" (BAPTISTA, 2010, p. 07). 
As discussões teóricas sobre a alfabetização, também a partir da década de 1980, tiveram a inclusão de uma nova palavra ao vocabulário: letramento. Segundo Soares (2006), Mary Kato foi uma das primeiras autoras a utilizar a palavra letramento e, desde então, "a palavra torna-se cada vez mais frequente no discurso escrito e falado de especialistas" (SOARES, 2006, p. 15).

Diante disso, surgem alguns questionamentos: O que é letramento? Qual sua importância para o âmbito da alfabetização? Podemos utilizar alfabetização e letramento como palavras sinônimas? Para responder estes questionamentos, Soares (2006, p. 17, grifos da autora), colabora ao afirmar que:

Trata-se, sem dúvida, da versão para o Português da palavra da língua inglesa literacy. Etimologicamente, a palavra literacy vem do latim littera (letra), com o sufixo $-c y$, que detona qualidade, condição, estado, fato de ser [...]. Ou seja: literacy é o estado ou condição que assume aquele que aprende a ler e escrever. Implícita nesse conceito está a ideia de que a escrita traz consequências sociais, culturais, políticas, econômicas, cognitivas, linguísticas, quer para o grupo social em que seja introduzida, quer para o indivíduo que aprenda a usá-la.

Assim, letramento é o resultado da apropriação da escrita, é a condição que adquire o indivíduo que aprende a ler e escrever. Desse modo, não basta saber ler e escrever, quem aprende a linguagem escrita precisa saber fazer uso da leitura e da escrita e saber viver em uma cultura que faz uso desta linguagem com frequência.

Referindo-se aos anos iniciais do Ensino Fundamental, Kato (1986) afirma que a escola tem a função de introduzir a criança à cultura letrada, tornando-a um sujeito capaz de fazer uso da linguagem escrita para suas necessidades individuais. Assim como a criança do Ensino Fundamental, ressaltamos que as crianças da Educação Infantil têm condições de utilizar linguagem escrita em práticas sociais.

Portanto, introduzir a criança no mundo da escrita é um grande desafio, porque os conceitos de alfabetização e letramento trazem consigo uma compreensão da linguagem escrita como produção cultural e, vistos desse modo, é preciso que todos tenham o direito de apropriar-se dela. 
Inserir a criança no mundo da escrita é mais que alfabetizá-la, se entendermos por alfabetização apenas o domínio do código; ou é iniciar a alfabetização, se compreendermos por alfabetização a inclusão em um universo cultural complexo em que a escrita aparece como mediadora de valores e de formas de conhecimento. Nessa lógica, o processo de letramento (ou alfabetização) começa antes do ensino fundamental e não se interrompe sequer com terminalidade da escolaridade regular. Letramento (ou alfabetização), nesse sentido, significa viver no mundo da escrita, dominar os discursos da escrita, ter condições de operar com os modos de pensar e produzir da cultura escrita (BRITTO, 2005, p. 16).

Ao compreender o processo de ensino e aprendizagem da linguagem escrita como introdução da criança no mundo da escrita, na perspectiva da alfabetização e letramento como unidade indissociável, é preciso refletir sobre alguns modos de organização do ensino que marcaram a história da alfabetização no Brasil. Nesse sentido, Mello (2010), ao rememorar seu processo de aprendizagem da leitura e da escrita, traz à tona a não significância desse aprender, com frases vazias de relações com o cotidiano e quase ficcionais, como "A barriga do bebê é grande". Afirma a autora que ela e os demais colegas não se perguntavam "como a barriga do bebê podia ser grande se os bebês são pequenos por definição [por que] o fato é que o significado da palavra escrita não interessava naquele momento, pois estávamos aprendendo a relacionar sons com letras, nada mais! O restante viria depois!" (MELLO, 2010, p. 44, passim).

A ênfase trazida pela autora, ao relembrar como foi alfabetizada, remete à reflexão sobre conteúdo e método adotados na alfabetização. Quando o aspecto técnico da escrita é a essência, o significado e, assim, também a função social da escrita, é posto como supérfluo. Por isso, "quando começaram a nos perguntar o significado do que tínhamos acabado de ler (no ensino médio ou na faculdade), tínhamos que voltar a ler o texto que acabáramos de ler" (MELLO, 2010, p. 45).

Portanto, o aspecto técnico da escrita é importante. Entretanto, apropriar-se de um sistema de códigos e símbolos como é a linguagem escrita requer a compreensão de que a escrita é a comunicação de algo destinado a alguém, com uma finalidade; ou seja, ela é uma representação da realidade, um modo de expressão criado, historicamente, para a vida em sociedade. Se a escrita é um modo de expressão, quem escreve e lê precisa compreendê- 
la como tal, ler uma palavra ou texto e saber qual a intencionalidade de sua autoria e o que se pretende comunicar.

A questão que emerge da compreensão desse processo é a contribuição da Educação Infantil para a apropriação da linguagem escrita. De acordo com Baptista (2010, p. 03),

Os resultados obtidos pelas pesquisas baseadas na psicogênese da leitura e da escrita (Ferreiro e Teberosky: 1985) são evidências de que as crianças, desde muito cedo, se perguntam sobre o funcionamento da linguagem escrita, jogam com suas possibilidades, criam hipóteses, inventam regras, imaginam meios de utilizá-la e de com ela interagir. Desde bem pequenas, as crianças são sujeitos que, na sua interação com os signos e símbolos, lhes atribuem distintos significados e usos.

Assim, desde pequenas, as crianças pensam sobre a linguagem escrita e elaboram seus próprios significados e usos para aquilo que as rodeia. Para tanto, é necessário que o ambiente em que elas estejam seja favorável para esta função. Ao considerar que, cada vez mais, as crianças estão na escola desde cedo, a Educação Infantil tem a função de contribuir para o letramento destas crianças. Nesse sentido, Mello (2010, p. 47) contribui ao enfatizar que

Vygotsky estabelece algumas diretrizes para esse processo. Em primeiro lugar, afirma o autor, aprender a ler e escrever precisa ser uma necessidade para a criança. Como se faz isso? Sabemos que é a partir das vivências que nascem as necessidades. Por isso, a melhor forma de criar a necessidade de aprender a ler e a escrever nas crianças é usar a escrita junto com elas, crianças, em situações verdadeiras em que a escrita seja necessária.

As necessidades impulsionam a criança no processo de ensino e aprendizagem. Quando a criança vivencia a escrita e a leitura em seu dia a dia, por exemplo, na escrita e leitura de um bilhete, uma lista de compras ou outra situação do cotidiano da escola, ela tem a possibilidade de atribuir uma função social para a escrita. Compreender que a leitura e escrita possuem uma importância social cria, também, motivos pessoais para sua apropriação por parte da criança, ou seja, uma necessidade. Nesse sentido, as práticas em 
que o professor desempenha o papel de escriba e os autores são as crianças tornam-se importantes no cotidiano da Educação Infantil (MELLO, 2010).

Algo essencial, no modo de conceber a leitura e escrita na Educação infantil é que não se trata de preparar a criança para a alfabetização sistemática, atribuição dada à Educação Infantil durante algum tempo (BAPTISTA, 2010). Trata-se, por outro lado, de garantir que a criança seja, desde pequena, participante da cultura em que vive, ou seja, de uma cultura letrada.

A literatura na Educação Infantil assume um papel importante na constituição mesma das crianças, ao possibilitar material simbólico com o qual as crianças apropriam-se da cultura historicamente produzida pela humanidade e, assim, pensarem sobre si mesmos e suas experiências coletivas e individuais. Na próxima sessão, apresentam-se algumas considerações acerca da relação literatura e Educação Infantil.

\subsection{Literatura, criança e Educação Infantil}

Desde que nasce um bebê, a comunicação dele com as pessoas a sua volta ocorre por meio da linguagem: nas cantigas de ninar, na conversa com seus familiares em momentos de cuidado e carinho (CADEMARTORI, 2014). Deste contato com a palavra, o bebê, aos poucos, sente a necessidade de, também, comunicar-se por meio dela.

Ao promover e aprimorar a relação da criança com a linguagem, convém não perder de vista que ouvir e falar são atividades primárias, enquanto leitura e escrita são atividades básicas. As primeiras se desenvolvem espontaneamente; as segundas requerem formalização. Para passar de um tipo de atividade a outro, é preciso ter adquirido certo grau de consciência da estrutura da língua (CADEMARTORI, 2014, p. 36).

Assim, a apropriação da linguagem escrita e o contato com o livro como mídia que possibilita o início desta apropriação não é espontâneo na criança. Aprender a manusear, ler, interpretar um livro é uma experiência pessoal da criança; entretanto, cabe ao professor possibilitá-la. Ainda segundo a autora, o que se espera de um livro para crianças é que, 
[...] ao explorá-lo brincando, adquira, de modo próprio e gradativo, de acordo com seu próprio ritmo, familiaridade com a estrutura da língua, que ela viva experiências de linguagem. E que isso seja feito ludicamente. Que seja divertido descobrir as possibilidades combinatórias da língua, suas potencialidades, seus recursos de expressão (CADEMARTORI, 2014, p. 36).

A ludicidade no discurso literário ocorre no emprego de signo e significado com formas variadas. Assim, pode-se afirmar que "tanto as crianças quanto a literatura subvertem a ordem, criando múltiplas formas de discurso na tentativa de apreender, ressignificar e modificar os sentidos" (BAPTISTA, 2010, p. 05).

Assim, a literatura infantil contribui para a formação do leitor, proporcionada pela experiência literária com uma manifestação artística, proveniente da cultura letrada. Além disso, Baptista (2010, p. 05) enfatiza sua contribuição na própria constituição dos sujeitos, ao oferecer às crianças "o material simbólico inicial para que possam ir descobrindo não apenas quem elas são, mas também quem elas querem e podem ser [...]".

Nesta concepção de leitura e escrita como ampliação do material simbólico da criança, na Educação Infantil, segundo Britto (2005, pp. 18-19),

[...] ler com os ouvidos e escrever com a boca (situação em que a educadora se põe na função de enunciadora ou de escriba) é mais fundamental do que ler com os olhos e escrever com as próprias mãos. Ao ler com os ouvidos, a criança não apenas se experimenta na interlocução com o discurso escrito organizado, como vai compreendendo as modulações de voz que se anunciam num texto escrito. [...] Se lermos uma história com (com, e não para) uma criança que ainda não conhece o sistema de escrita e pedirmos para ela recontar o que leu, ela certamente não dirá a história com as mesmas palavras do texto original, [...] mas demonstrará que compreendeu o texto (que interagiu com ele). Demonstrará, enfim, que leu o texto e o ressignificou.

Desse modo, a leitura com os ouvidos ocorre quando o adulto lê em voz alta e faz uso das mais variadas entonações para dar vida aos personagens e cenas que descreve. Já a escrita com a boca requer que a criança reconte a história, expresse por meio de palavras aquilo que ouviu, faça a sua interpretação da história contada e o professor, como escriba, registra. O princípio que orienta essa ação pedagógica é o da experiência com a cultura letrada que a rodeia, incluindo as características da oralidade e da escrita. 
Cabe ressaltar que a Literatura Infantil, como gênero, nasceu com Charles Perrault. Entretanto, segundo Coelho (2008), somente cem anos depois, a partir das pesquisas realizadas pelos Irmãos Grimm (Jacob e Wilhelm), ela foi constituída e teve início sua expansão pela Europa e pelas Américas.

Participantes do Círculo Intelectual de Heidelberg, os Grimm - filósofos, folcloristas, estudiosos da mitologia germânica empenhados em determinar a autentica língua alemã [...] - entregam-se à busca das possíveis invariantes linguísticas, nas antigas narrativas, lendas e sagas que permaneciam vivas, transmitidas de geração para geração, pela tradição oral. [...] acabaram por formar a coletânea que é hoje conhecida como Literatura Clássica Infantil. Entre os contos mais conhecidos estão: $A$ Bela Adormecida; Branca de Neve e os Sete Anões; Chapeuzinho Vermelho; A Gata Borralheira; O Ganso de Ouro; Os Sete Corvos; Os músicos de Bremem; A Guardadora de Gansos; Joaozinho e Maria; O Pequeno Polegar; As Três Fiandeiras; $O$ Príncipe Sapo e dezenas de outros, que correm o mundo (COELHO, 2008, p. 29, grifos da autora).

Com o objetivo de preservar um patrimônio tradicional da Alemanha e colocá-lo ao alcance de todos, os Irmãos Grimm narraram contos "em prosa e numa linguagem bem próxima da oralidade, de um jeito parecido ao que era falado pela gente do povo que contava essas histórias havia séculos [...]" (MACHADO, 2002, p. 71). Além disso, ainda de acordo com a referida autora, os contos de fada possuem um alto nível de qualidade artística e força natural "atestados pela sua universalidade e sua permanência" (MACHADO, 2002, p. 69).

De acordo com Debus e Domingues (2015, p. 59), os contos de fadas existem e persistem na contemporaneidade:

Contados ao redor de fogueiras, recontados em ambientes familiares com o intuito de entreter os adultos e educar as crianças, adaptados para o cinema, para o teatro ou para grandes musicais, temas de inspiração para parques temáticos, os contos de fadas são fontes inesgotáveis de inspiração para a humanidade. E essa fonte parece mesmo inesgotável à medida que acompanha o desenvolvimento da tecnologia, se renova e se faz presente a cada nova geração. 
Diante do exposto, optamos pelos contos de fadas para o trabalho de intervenção realizado, apresentando, a seguir, a análise dos dados obtidos com base no referencial teórico adotado.

\section{BRANCA DE NEVE E OS SETE ANÕES: ENTRE MAÇÃS ENFEITIÇADAS E BILHETES CRIADOS}

O movimento que se faz, nesta sessão, busca reconstruir a realidade investigada, a partir de um olhar teórico. O questionamento que fundamenta a análise consiste em: como assegurar à criança o direito à cultura letrada e experimentar diferentes modos de pensar a escrita desde a Educação Infantil a partir dos contos de fadas?

Para responder esta questão, a primeira ação de pesquisa e, também, ação pedagógica, foi a criação da Sacola Viajante, um artefato construído de tecido com o objetivo de servir como invólucro para o livro que fosse levado pela criança para casa.Isso foi motivado e possível porque a instituição tinha um acervo significativo oriundo do Programa Nacional Biblioteca na Escola (PNBE), que ficava indisponível para as crianças ${ }^{3}$.

Desse modo, por ordem de sorteio, cada criança levou um livro de literatura da biblioteca do Centro de Educação Infantil (CEI) a sua escolha; constatou-se que a maioria levou livros que já tinham sido lidos na sala. A intenção com o envio da sacola é que houvesse interação familiar, ou seja, para que fosse possível uma leitura compartilhada com a família no fim de semana. Acompanhando o livro seguiu, também, um caderno de registros, no qual cada família tinha um espaço para relatar como foi a experiência.

\footnotetext{
${ }^{3}$ O Programa Nacional Biblioteca da Escola (PNBE), desenvolvido em 1997, contempla as instituições de Educação Infantil desde 2008. O atendimento é feito em anos alternados: em um ano são contempladas as instituições de Educação Infantil, de Ensino Fundamental (anos iniciais) e de educação de jovens e adultos. Já no ano seguinte são atendidas as escolas de Ensino Fundamental (anos finais) e de Ensino Médio.
} 


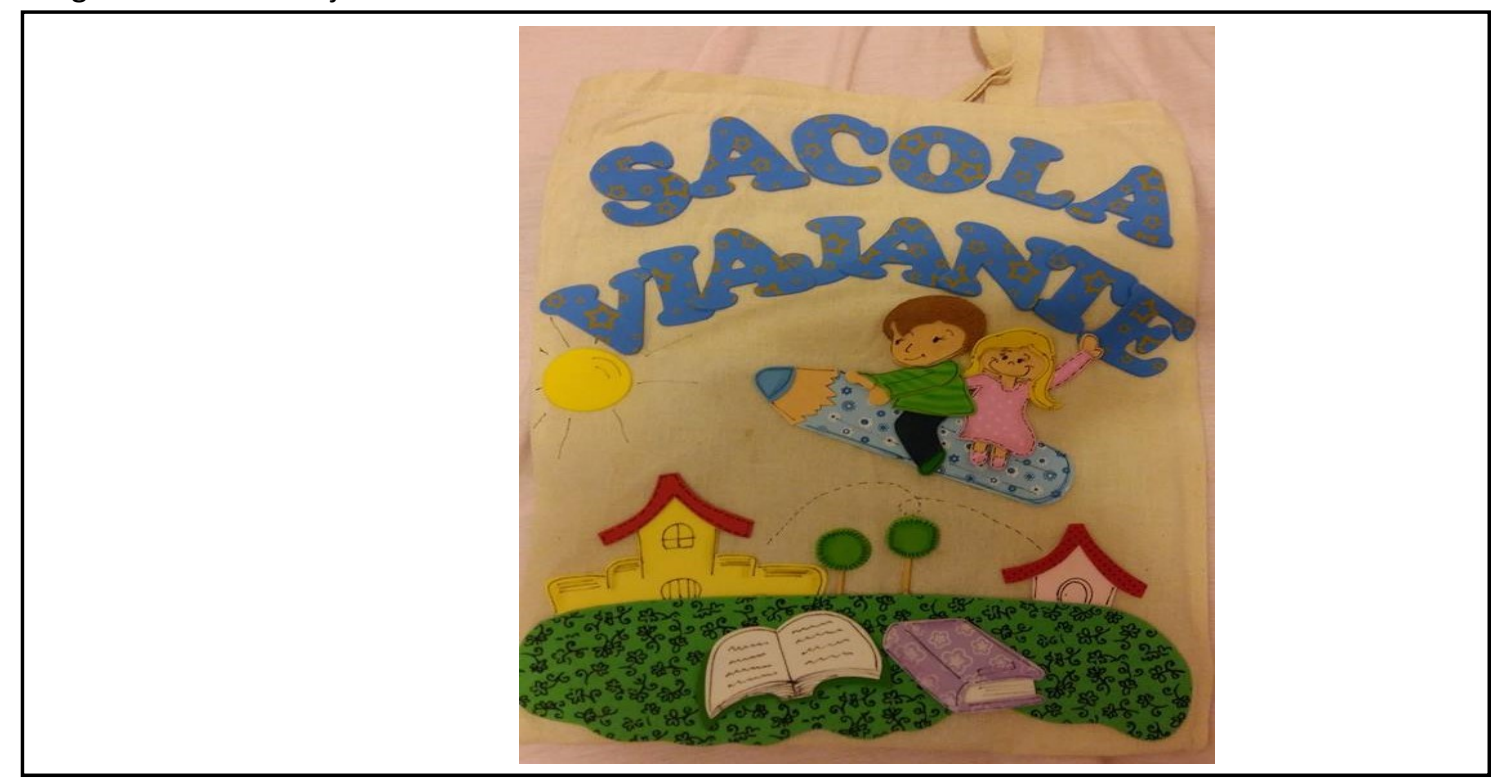

Fonte: Acervo das pesquisadoras.

No retorno da Sacola Viajante, cada criança foi convidada a recontar a história aos colegas, objetivando o respeito à voz da criança e sua compreensão do lido; produtora de cultura que é, "assume um papel importante não apenas na formação de leitores, mas também na própria construção do sujeito. Ao ouvir, ler e contar histórias, a criança vivencia a oportunidade de descobrir outros significados para a experiência humana" (BAPTISTA, 2012, p. 30).

Esta experiência tornou-se significativa tanto nos registros, nos quais as famílias descreviam muito interesse por parte da criança pela leitura e manuseio do livro, bem como no momento do reconto, na sala de referência, das histórias lidas em casa. Em alguns casos, "as crianças colocavam o dedo em cada palavra em sinal de que estavam lendo aquilo que estava escrito no livro" (DIÁRIO DE CAMPO, 08 de agosto de 2015).

Em relação aos registros das famílias, muitos relataram a leitura dos contos como um momento de interação da criança com a história e seus significados, conforme relato da mãe de uma das crianças ${ }^{4}$ :

\footnotetext{
${ }^{4}$ Ao longo do texto, para preservar a identidade de cada criança, utiliza-se a letra C (inicial da palavra criança) e um número que identifica cada uma.
} 
[...] adorou a história, pediu para contar várias vezes e depois ele mesmo contou a história para nós, acrescentando outros temas da imaginação dele, adorou mesmo a sacola viajante, foi muito bom para nós, pais, saber como se interessa por contos. Obrigada por tudo (CADERNO DE REGISTROS, 10 agosto de 2015$)$.

Na continuidade do projeto, as histórias dos Irmãos Grimm foram trazidas para enriquecer esta experiência com contos feéricos. Inicialmente foi trazida uma foto dos irmãos e lida para as crianças sua biografia, com apoio no texto de Carvalho e Yamazato (2015, s.p.):

Era uma vez, dois irmãos que adoravam uma história, principalmente aquelas que, de boca em boca, atravessam gerações, traduziam desejos e emoções e tocavam a alma das pessoas. Para que essas narrativas não fossem apagadas pelo tempo, eles resolveram reuni-las em um livro.

Coletivamente, as crianças foram questionadas: o que você e sua família costumam escrever para não esquecer? As crianças contaram suas vivências, lembrando de bilhetes com recados para outros familiares, receitas, listas do mercado, entre outros. Em relação a ações como esta, Mello (2010, p. 49) colabora ao afirmar que

Não começamos propondo atividades de escrita para a criança, mas estimulando e exercitando seu desejo de expressão e sua expressão em diferentes linguagens. Fazemos isso quando a deixamos contar suas histórias de vida e de imaginação para o grupo- e também quando contamos histórias para elas. Também estimulamos e exercitamos seu desejo de expressão quando solicitamos rotineiramente sua opinião sobre os problemas e os temas discutidos na sala, quando solicitamos sua participação na solução de problemas que surgem na turma, quando avaliamos todos juntos o dia vivido na escola.

Desse modo, ao pensar sobre o uso da escrita em suas vivências, as crianças aproximam-se da função social da escrita e, no compartilhamento dessas experiências com os colegas, expressam aquilo que pensam, elaboram verbalmente seu pensamento e ampliam sua própria compreensão de escrita ao ouvir os colegas. 
Para, assim como os Irmãos Grimm, não nos esquecermos de sua história, solicitamos que as crianças ilustrassem, coletivamente, a biografia dos autores alemães. Ao final desta atividade, colamos em nossa sala a produção das crianças.

Para continuar o trabalho com as histórias dos Irmãos Grimm, em outro momento do projeto, utilizamos ilustrações de algumas histórias destes autores e questionamos quais eram conhecidas pelas crianças. As ilustrações eram das seguintes histórias: Branca de neve; Chapeuzinho vermelho; O príncipe sapo; Rapunzel; Cinderela; Os músicos de Bremem; Rapunzel; João e Maria.

Foi observado que a maioria das crianças conhecia os títulos e recontaram parte das histórias oralmente. Então, foi montado um gráfico com a história preferida de cada criança. Nele, cada uma desenhou sua história favorita em um quadrado de papel e a professora, como escriba, escreveu o nome da história. A contagem coletiva foi realizada e observado que a história Branca de Neve e os sete anões foi a preferida da turma, com 5 votos.

Segundo Mello (2010), primeiro deve-se usar a escrita em sua função social, e só depois disso apresentar seu aspecto técnico. Desse modo, primeiro a criança convive bastante com a escrita e a leitura, entende para que servem e depois "é que devemos começar a ensinar como se faz para escrever" (MELLO, 2010, p. 47).

Para promover mais uma experiência com textos lidos, foi trabalhado Branca de Neve, dos Irmãos Grimm, adaptado por Laurence Bourguignon, a história preferida da turma pelo gráfico.

O diálogo com as crianças sobre o livro foi determinante para que se compreendesse a história e alguns conceitos que ela traz como, por exemplo, da beleza, de atitudes de respeito ou não com o outro. Foram relacionadas ações positivas e negativas do cotidiano com as personagens da história, por exemplo, as atitudes da madrasta, e conversado, também, sobre a beleza interior de cada pessoa.

Em seguida, foi apresentada às crianças uma caixa embrulhada, e explicado que essa era uma caixa surpresa, que tinha algo que era preciso descobrir o que era. Neste momento, o objetivo era incentivar a ação investigativa na elaboração de perguntas para descobrir o que havia dentro da caixa e, também, a elaboração de hipóteses, expressadas 
pela linguagem oral, pela iniciativa de falar aquilo que se pensa. Conforme as crianças foram avançando nas respostas, houve facilitação dizendo: "é vermelha", "é redonda", "é de comer"... até chegarem na resposta: MAÇÃ.

Dentro da caixa havia, também, um bilhete escrito pela madrasta, contando a uma amiga que novamente tentaria enfeitiçar Branca de Neve, conforme segue na Imagem 03:

Imagem 02: Bilhete escrito pela madrasta

“Oi amiga... aqui está a nova maçã enfeitiçada. Já pode deixar na porta da casa da Branca de Neve. Desta vez ela não escapa. Obrigada por me ajudar, querida. Ass.: Madrasta" (DIÁRIO DE CAMPO, 01 de setembro de 2015).

Fonte: Acervo das pesquisadoras.

Em conversação, foi solicitado que as crianças encontrassem um modo de avisar a personagem Branca de Neve que algo estava para acontecer: "O que podemos fazer quando queremos falar com alguém que está muito longe? Escrever um bilhete foi a resposta das crianças!" (DIÁRIO DE CAMPO, 01 de setembro de 2015).

De acordo com Mello (2010, p. 47),

Sabemos que é a partir de vivências que nascem as necessidades. Por isso, a melhor forma de criar a necessidade de aprender a ler e a escrever nas crianças é usar a escrita junto com elas, crianças, em situações verdadeiras em que a escrita seja necessária: corresponderse com alguém distante, escrever junto com a turma as regras de convivência e retomar diariamente a leitura desses combinados entre a turma, manter junto com a turma um diário do que acontece a cada dia na escola.

A turma, na sequência, escreveu um bilhete para Branca de Neve. A professora, novamente como escriba, registrou a produção textual: "Branca de Neve... A madrasta vai te enviar uma nova maçã enfeitiçada, cuidado! Não coma! Ela é muito malvada! Ass.: Creche IV" (DIÁRIO DE CAMPO, 01 de setembro de 2015). 
Logo, surgiu uma dúvida: como se poderia entregar o bilhete para a Branca de Neve? Depois de várias propostas, uma criança sugeriu que se colocasse no correio. Aconteceu, então, o seguinte diálogo entre duas crianças:

$C^{1}$ : Mas, se está no correio quem vai entregar o bilhete para a Branca de Neve?"

$\mathrm{C}^{2}$ : - O carteiro.

$\mathrm{C}^{1}$ : Mas como ele sabe onde ela mora?

$C^{2}$ : Os carteiros sabem onde todo mundo mora! (DIÁRIO DE CAMPO, 01 de setembro 2015).

No diálogo estabelecido entre as duas crianças, ressalta-se a importância da vivência com o outro na própria apropriação de cultura, ou seja, a experiência prévia de cada um é constituída "pela incorporação da experiência social, histórica e coletiva" (BAPTISTA, 2012, p. 95). Neste sentido, a imaginação de cada um é constituída e orientada pelas experiências com/do outro.

O bilhete foi colocado na caixinha de correio da escola e, no dia seguinte, por iniciativa própria, algumas crianças foram olhar se o carteiro já teria passado. O bilhete não estava mais lá. Elas ficaram eufóricas. Alguns dias se passaram e, em todos, se conferiria se havia chegado uma resposta da Branca de Neve. Depois de 3 dias a resposta foi recebida: "Queridas crianças, muito obrigada por me avisarem sobre a maçã enfeitiçada. Para garantir, vou plantar uma macieira aqui e só comerei as minhas maçãs. Com carinho, Branca de Neve" (DIÁRIO DE CAMPO, 04 de setembro de 2015).

De acordo com Machado (2002, p. 77),

Ler uma narrativa literária (como ninguém precisa ensinar, mas cada leitor vai descobrindo à medida que se desenvolve) é um fenômeno de outra espécie. Muito mais sutil e delicioso. Vai muito além de juntar letras, formar sílabas, compor palavras e frases, decifrar seu significado de acordo com o dicionário. É um transporte para outro universo, onde o leitor se transforma em parte da vida de um outro, e passa a ser alguém que ele não é no mundo cotidiano.

Este transporte para outro universo, anunciado por Machado, fica ainda mais perceptível quando o adulto conta a história para as crianças ou, em outras palavras, como 
já mencionado, quando a criança faz a leitura pelos os ouvidos. Nesta perspectiva de contato com o mundo da leitura e da escrita, Soares (1998, p. 20) afirma que "não basta apenas saber ler e escrever, é preciso também saber fazer uso do ler e escrever, saber responder às exigências de leitura e escrita que a sociedade faz continuamente".

Com isso, iniciar a compreensão do uso da leitura e da escrita desde a primeira infância torna-se algo essencial, pois, após a realização das atividades até então analisadas, outro momento tornou-se significativo para a turma:

Depois de algum tempo, as crianças encontraram, no parque, um bilhete no chão. $\mathrm{Na}$ hora, já pediram para que eu lesse, queriam saber se era para a nossa turma. O bilhete era um recadinho mandado de uma estagiária para a outra e dizia apenas: "Gladys, não se esquece de mostrar pra ela. Camila." (DIÁRIO DE CAMPO, 09 de setembro de 2015).

A partir desse bilhete ${ }^{5}$, eles levantaram várias hipóteses do que queria dizer. Como havíamos trabalhado com bilhetes, as crianças acharam que aquele, como os outros, também era para a turma. Foi explicado que o bilhete tinha sido deixado no parque por esquecimento ou distração, mas que não era para a nossa turma. Eles queriam entender o que estava escrito, mas, como eram poucas informações, não havia como entender o que o destinatário queria transmitir ao seu receptor.

A situação ocorrida com o caso do bilhete demonstra que a aquisição da leitura e a escrita, assim como os outros conceitos, precisa tornar-se uma necessidade para a criança (MELLO, 2010). O interesse em saber o que está escrito é o primeiro passo para que, mais tarde, eles próprios queiram ler outros bilhetes, contos, livros, etc.

\section{CONSIDERAÇÕES FINAIS}

A compreensão das crianças como atores sociais que participam, apropriam-se e significam a cultura e as experiências que vivenciam requer o contato com a cultura letrada desde a mais tenra idade. Isto porque a escrita é um sistema de signos essencial na

\footnotetext{
${ }^{5}$ Em relação ao bilhete encontrado, os nomes das pessoas envolvidas foram mantidos para não alterá-lo.
} 
sociedade atual e, tendo em vista sua abrangência, as crianças demonstraram interesse por seu funcionamento ao conhecê-la por meio de livros, revistas, jornais, entre outros.

Nesta perspectiva, ressalta-se, neste artigo, a importância de práticas pedagógicas que enfatizem a leitura e escrita como produção cultural desde a Educação Infantil. Buscou-se contrapor a ideia de ensinar a ler e escrever na Educação Infantil e defende-se, a partir das leituras realizadas e da análise dos dados obtidos na coleta de dados, o trabalho com a função social da escrita e situações nas quais a criança sinta a necessidade de ler e escrever.

Para isso, os contos de fadas constituem uma forma de produção cultural que tem significado próprio, elementos diferentes em cada conto, e formas de expressão que Ihes dão sentido, tanto no decorrer da história, quanto em seu final. $\mathrm{O}$ adulto, no caso deste estudo, em especial o professor, é quem apresenta e seduz as crianças para o maravilhoso mundo dos contos, onde o pacto ficcional efetiva-se e surgem fadas, bruxas, animais falantes, entre outras personagens.

Não é necessário que as crianças pequenas compreendam o aspecto técnico da escrita para construir significados ao escutar um conto, perceber o uso que o autor fez de expressões, ideias, valores e sentimentos para contar uma história. Do mesmo modo, não é necessário este aspecto para formular hipóteses, criar outras histórias, personagens e apropriar-se da escrita em sua função social, ou seja, apropriar-se de uma cultura letrada.

Em síntese, o trabalho com a linguagem escrita na Educação Infantil justifica-se pela necessidade de interação da criança com o mundo que a rodeia, com uma importante produção cultural da humanidade que está presente em seu cotidiano. Para tanto, as especificidades da primeira infância devem ser respeitadas e valorizadas com práticas que considerem o modo de ser das crianças pequenas.

\section{REFERÊNCIAS}

BAPTISTA, Monica Correia. Leitura literária na primeira infância: a experiência da bebeteca Can Bujtosa em Barcelona. In: MACHADO, Maria Zélia V. (Org.). A criança e a leitura literária: livros, espaços, mediações. Rio de Janeiro: Positivo, 2012. 
Alfabetização e letramento em classes de crianças menores de sete anos. In: XV ENDIPE - Encontro Nacional de Didática e Prática de Ensino: Convergências e tensões no campo da formação e do trabalho docente: políticas e práticas educacionais. Faculdade de Educação da UFMG. Belo Horizonte, 2010.

BRASIL. Ministério da Educação. Secretaria de Educação Básica. Diretrizes curriculares nacionais para a educação infantil / Secretaria de Educação Básica. Brasília: MEC, SEB, 2010.

BRITTO, Luiz Percival Leme. Letramento e alfabetização: implicações para a educação infantil. IN: FARIA, Ana Lúcia G; MELLO, Suely Amaral (Orgs.). 0 mundo da escrita no universo da pequena infância. São Paulo: Autores Associados, 2005. p.5-21.

BUSS-SIMÃO, Márcia; ROCHA, Eloisa C.; GONÇALVES, Fernanda. Percursos e tendências da produção científica sobre crianças de 0 a 3 anos na ANPEd. Revista Brasileira de Estudos Pedagógicos (online). Brasília, v. 96, n.242, p.96-111, jan/abr. 2015.

CADEMARTORI, Ligia. As narratividades. In: BAPTISTA, Mônica et al. (Orgs). Literatura na educação infantil: acervos, espaços e mediações. Brasília: MEC, 2014.

CARVALHO, Gisleine; YAMAZATO, Cristiane. O livro encantado dos Irmãos Grimm. Versão online disponível no site: $<$ http://educarparacrescer.abril.com.br/leitura/livro-encantadoirmaos-grimm-729486.shtml> Acessado em 10 jul. de 2015.

COELHO, Nelly Novaes. Os contos de fadas: símbolos - mitos - arquétipos. São Paulo: Paulinas, 2008.

DEBUS, Eliane; DOMINGUES, Chirley. Branca de Neve e as sete versões: uma manifestação do insólito ficcional. In: DEBUS, Eliane; MICHELLI, Regina (Orgs.). Entre fadas e bruxas: o mundo feérico dos contos para crianças e jovens. Rio de Janeiro: Dialogarts, 2015.

GRIMM, Jacob e Wilhelm. Branca de Neve. Adaptação Laurence Bourguignon; ilustrações Quentin Gréban; tradução Carlos Frederico Barrère Martin. São Paulo: Comboio de Corda, 2013.

KATO, Mary. No mundo da escrita: uma perspectiva psicolinguística. São Paulo: Ática, 1986.

MACHADO, Ana Maria. Como e por que ler os clássicos universais desde cedo. Rio de Janeiro: Objetiva, 2002.

MELLO, Suely Amaral. Contribuições da Educação Infantil para a formação do leitor e produtor de textos. In: FLORIANÒPOLIS. Prefeitura Municipal de Florianópolis. Secretaria Municipal de Educação. Diretrizes Educacionais - pedagógicas para a Educação Infantil. Florianópolis, 2010. 
SILVA, Isabel de Oliveira e; LUZ, Iza Rodrigues da; FARIA FILHO, Luciano Mendes de. Grupos de pesquisa sobre infância, criança e educação infantil no Brasil: primeiras aproximações. Revista Brasileira de Educação, v. 15, n. 43 jan./abr., p. 84-98, 2010.

SOARES, Magda. Letramento e alfabetização: as muitas facetas. CD-ROM da $26^{\circ}$ Reunião Anual da ANPED. Caxambu. GT 10 - Alfabetização, leitura e escrita, 2003.

. Letramento: um tema em três gêneros. Belo Horizonte: Autêntica, 1998.

STRENZEL, Giandréa Reuss. A produção científica sobre educação infantil no Brasil nos programas de pós-graduação em educação. In: 23a REUNIÃO ANUAL DA ANPEd, 2000, Caxambu. Anais... Rio de Janeiro: ANPEd, 2000.

RECEBIDO EM 20 DE JUNHO DE 2015.

APROVADO EM 19 DE SETEMBRO DE 2016. 